\title{
Carbon and energy flux constraints in continuous cultures of A/caligenes eutrophus grown on phenol
}

\author{
David Leonard and Nicholas D. Lindley \\ Author for correspondence: Nicholas D. Lindley. Tel: +33561 559489. Fax: +33561559400. \\ e-mail: lindley@insa-tlse.fr
}

Centre de Bioingénierie Gilbert Durand, UMR CNRS/INSA and Lab. Ass. INRA, Institut National des Sciences Appliquées, Complexe Scientifique de Rangueil, 31077 Toulouse cedex 4, France

\begin{abstract}
The growth behaviour of Alcaligenes eutrophus on phenol was investigated in continuous cultures to identify the phenomena limiting both growth efficiency and substrate degradation rates. It was shown that the fixed stoichiometry of the meta pathway of phenol degradation, leading to equimolar quantities of pyruvate and acetate, and the structure of the central pathways, which do not allow gluconeogenesis of acetate during growth on phenol, provoke the accumulation of polyhydroxybutyrate (PHB) under certain growth conditions. Acetate is predominantly used as an energy source and PHB accumulates when the cells are carbon-limited rather than energy-limited. The maximum rates of phenol degradation can be attributed to the expression of the enzymes of the catabolic pathway. This is particularly true of phenol hydroxylase and 2hydroxymuconate semialdehyde (2-hms) dehydrogenase, whose substrates accumulated to physiologically significant concentrations at high growth rates. Indeed the concentration of 2-hms that accumulated in the medium indicated that this enzyme was substrate-saturated at maximum growth rates. However, the specific activity profiles of other catabolic enzymes associated with phenol degradation were close to the estimated flux through the pathway. This suggests a complex control structure in which several enzymes contribute to the control of pathway flux, as would be expected in a catabolic pathway.
\end{abstract}

Keywords: Alcaligenes eutrophus, 2-hydroxymuconate semialdehyde dehydrogenase, phenol metabolism, meta pathway, polyhydroxybutyrate

\section{INTRODUCTION}

Phenol and structurally related compounds are organic pollutants, which are toxic at relatively low concentrations and are listed as priority pollutants by the US Environmental Protection Agency (Ghisalba, 1983). They can be detected in industrial effluents from chemical plants, oil refineries and agrochemistry plants (manufacturing herbicides or pesticides). Phenol can be removed by biological treatment, since many bacteria and fungi are capable of using aromatic compounds as the sole source of both carbon and energy. The two main metabolic pathways for the aerobic degradation of phenol by micro-organisms are the ortho and meta cleavage pathways. The genes necessary for the expression of both these pathways can be either

Abbreviations: PHB, polyhydroxybutyrate; 2-hms, 2-hydroxymuconate semialdehyde. chromosome- or plasmid-encoded, depending upon the species examined. For example, the meta pathway is chromosome-encoded in Pseudomonas putida (Hill \& Robinson, 1975) but plasmid-encoded in Pseudomonas sp. CF600 (Nordlund et al., 1990), while the ortho pathway is chromosome-encoded in Acinetobacter calcoaceticus (Paller et al., 1995).

While phenol degradation has been extensively studied in various pseudomonads, Alcaligenes eutrophus has also received attention because of the large number of aromatic compounds it metabolizes via chromosomeencoded pathways (Johnson \& Stanier, 1971), and because of its plasmid-associated resistance to heavy metals (Mergeay et al., 1985), which are frequently encountered in polluted environments. In addition to these environmental applications, A. eutrophus has also been extensively studied for its capacity to accumulate polyhydroxybutyrate (PHB), an intracellular storage polymer, synthesized from acetyl-CoA, which is im- 
portant in the renewable plastics industry (Linko et al., 1993). Significant accumulation of this polymer occurs when cells are cultivated under various nutritional limitations in the presence of excess carbon substrate. Synthesis of PHB by constitutive enzymes is believed to be regulated by the intracellular concentrations of acetyl-CoA, CoASH, NADH and/or NADPH (Steinbüchel \& Schlegel, 1991).

Hughes \& Bayly (1983) demonstrated that phenol metabolism by $A$. eutrophus uses a chromosomeencoded meta cleavage pathway. The degradation endproducts of this catabolic pathway are pyruvate and acetaldehyde, which are further metabolized via the central pathways after conversion of the latter compound to acetyl-CoA. These authors also proposed that the genes of this catabolic pathway are organized in two functional units: a monocistronic operon comprising the phenol hydroxylase structural gene and a second operon comprising the six subsequent enzymes of the meta cleavage pathway. The primary substrate, phenol, is the only known inducer of these two operons and it has been proposed that a single regulatory protein may be responsible for the control of pathway expression, with the phenol hydroxylase gene under positive control, whereas the cat operon would be under negative control (Hughes \& Bayly, 1983). No molecular proof has substantiated this regulatory model for A. eutrophus and the genetic data available for other species indicate that different modes of regulation of these two operons occur depending on the strain and the genetic organization (Kukor \& Olsen, 1991; Herman \& Müller, 1995).

If this capacity to degrade phenol is to be exploited, the optimal conditions and potential limitations need to be established. Most water-treatment plants to some extent use continuous processes, with a waste outflow containing pollutant concentrations close to zero, and are therefore similar in principle to continuous-culture systems. In this study the capacity of A. eutrophus to degrade phenol at various dilution rates in chemostat culture was characterized and the possible rate-limiting aspects of the processes established by biochemical analysis of steady-state cultures.

\section{METHODS}

Bacterial strains and growth conditions. Alcaligenes eutrophus 335 (ATCC 17697) was obtained from LMG (Brussels, Belgium) and used throughout this study. A second strain of A. eutrophus 355, unable to grow on acetate after transposon mutagenesis and lacking detectable malate synthetase activity (unpublished results), was used to confirm that the glyoxylate shunt was not necessary for growth on phenol. This strain was derived by triparental mating to mobilize plasmid pUTlux $A B$, a $\mathrm{Tc}^{\mathrm{R}}$ and $\mathrm{Ap}^{\mathrm{R}}$ transposon delivery plasmid for mini-Tn5 luxAB into $A$. eutrophus, as described by Kristensen et al. (1995). For this the donor (Escherichia coli CM990 harbouring pUTlux $A B$ ), the recipient (A. eutrophus 335) and the helper (E. coli CM404, containing the $\mathrm{Km}^{\mathrm{R}}$ helper plasmid RK600) strains were grown separately overnight in Luria-Bertani (LB) medium (with antibiotics for the $E$. coli strains), washed with
$\mathrm{MgSO}_{4}(10 \mathrm{mM})$, mixed in a proportion of 1:5:1 and applied as $100 \mu \mathrm{l}$ drops on LB plates. After $8 \mathrm{~h}$, the cells were scraped off the surface, dispersed into $1 \mathrm{ml} \mathrm{MgSO}(10 \mathrm{mM})$, diluted as required and plated on mineral salts medium (see below) with gluconate $(20 \mathrm{mM})$ and tetracycline $\left(20 \mathrm{mg} \mathrm{l}^{-1}\right)$ for counterselection of the donor and helper E. coli strains. Acetatenegative strains were then selected as being unable to grow on mineral salts medium containing acetate $(20 \mathrm{mM})$ and tetracycline.

The mineral salts medium used for growth has been described previously (Ampe \& Lindley, 1995); the basal salt medium was adjusted to $\mathrm{pH} 7$ and was sterilized by autoclaving at $121^{\circ} \mathrm{C}$. A stock solution of potassium phosphate $(1 \mathrm{M}, \mathrm{pH}$ 7) was autoclaved separately and added to the sterile mineral salts medium at a final concentration of $40 \mathrm{mM}$. Phenol was filter-sterilized through membranes (pore size $0.2 \mu \mathrm{m}$ ) and added to the medium prior to inoculation. A 3.5 l Chemap fermenter (working volume $2 \mathrm{l}$ ) was used for both batch and chemostat cultures. The temperature was maintained constant at $30^{\circ} \mathrm{C}$, the $\mathrm{pH}$ was maintained at 7.0 with automatic addition of $\mathrm{KOH}(3 \mathrm{M})$, and the $\mathrm{O}_{2}$ partial pressure was maintained above $60 \%$ of air saturation (i.e. $>0.132 \mathrm{mM} \mathrm{O}_{2}$ dissolved in the medium) by modifying both the stirrer speed and the volumetric air flow rate. The bioreactor was inoculated with a $10 \%(\mathrm{v} / \mathrm{v})$ late-exponential-phase shake-flask culture grown on phenol $(5 \mathrm{mM})$ which was first aseptically centrifuged $(5000 \mathrm{~g}$ for $10 \mathrm{~min}$ at ambient temperature) and resuspended in fresh medium to remove any accumulated metabolites. The phenol concentration in the medium for batch growth was fixed at $5 \mathrm{mM}$ to avoid significant inhibition by the substrate, but this concentration was gradually increased to $42.5 \mathrm{mM}$ in the inflowing medium supply during continuous cultivation. This higher phenol concentration facilitated the removal of adequate cells for enzyme analysis without necessitating the removal of large samples liable to provoke perturbations to steady states. Steady states were considered to have been established after a minimum of five residence times and when cell concentration, residual substrate and enzyme concentrations had attained constant values. Changes to dilution rates were made in small steps, as described by Li \& Humphrey (1989) to avoid transitory accumulation of inhibitory concentrations of phenol leading to culture washout. Samples for determination of phenol and other extracellular metabolite concentrations were withdrawn directly from the bioreactor through a minipore membrane filtration unit to obtain cell-free culture samples directly.

Measurement of fermentation parameters. Biomass was measured by determining cell dry weight. A mean biomass formula of $\mathrm{C}_{4} \mathrm{H}_{6 \cdot 98} \mathrm{O}_{1 \cdot 84} \mathrm{~N}_{0.86}$ (with $3 \cdot 6 \%$ ash content), determined by elemental analysis (Ecole de Chimie, Toulouse, France), was used for elemental recovery calculations. All specific rates were calculated relative to the active biomass concentration (total cell mass minus the part represented by PHB) since this represents the true catalytic potential of the cells.

The phenol concentration for batch culture and chemostat washout experiments was analysed by HPLC using a Bio-Rad Aminex HPX-87H column $(300 \times 7.8 \mathrm{~mm})$ and the following operating conditions: temperature, $65^{\circ} \mathrm{C}$; mobile phase, $5 \mathrm{mM} \mathrm{H}_{2} \mathrm{SO}_{4}+7 \%$ (v/v) $\mathrm{CH}_{3} \mathrm{CN}$; flow rate, $0.8 \mathrm{ml} \mathrm{min}^{-1}$. Detection was made at $210 \mathrm{~nm}$ with a variable-wavelength UV detector and quantification was by integration of peak area. The residual phenol concentration in chemostat cultures was too low to be accurately quantified by HPLC experiments and was therefore measured by a more sensitive colorimetric method based on the rapid condensation of phenol with 4- 
aminoantipyrene, followed by oxidation to give a red product (Folsom et al., 1990).

$\mathrm{O}_{2}$ uptake and $\mathrm{CO}_{2}$ production were analysed by chromatographic analysis of inflowing and outflowing gas composition using a two-column separation technique (Porapack Q followed by a $0.5 \mathrm{~nm}$ molecular sieve column) with cathometer detection.

The PHB content of cells was estimated using the method of Aragao et al. (1996) and involved chromatographic detection of hydroxybutyrate after derivatization to a methyl ester.

Determination of enzyme activities. Approximately $50-100 \mathrm{mg}$ (wet wt) freshly harvested cells was washed twice in Tris/ $\mathrm{HCl}\left(\mathrm{pH} 7.5,50 \mathrm{mM}\right.$ ) at $4{ }^{\circ} \mathrm{C}$ and resuspended in $5 \mathrm{ml}$ Tris/carballylate buffer $(\mathrm{pH} 7.8 ; 9 \mathrm{mM}$ tricarballylic acid+ $35 \mathrm{mM}$ Tris/HCl) containing $\mathrm{MgCl}_{2}(5 \mathrm{mM})$ and glycerol $(20 \%, \mathrm{v} / \mathrm{v})$. The cells were disrupted by ultrasonication (four cycles of $20 \mathrm{~s}$ interspaced with $1 \mathrm{~min}$ periods of cooling on ice), and the resulting crude extracts were centrifuged $(15000 \mathrm{~g}$ for $10 \mathrm{~min}$ at $4^{\circ} \mathrm{C}$ ) to obtain soluble protein extracts, which were used to assay enzyme activities. The enzyme assays were performed by the methods described by the following authors: phenol hydroxylase, Schwien \& Schmidt (1982) except that buffer was at $\mathrm{pH} 7$; catechol 2,3-dioxygenase, Sala-Trepat $\&$ Evans (1971) except that $10 \%$ acetone was added to crude extracts prior to sonication; acetyl-CoA synthetase, Oberlies et al. (1980); isocitrate lyase and malate synthase, Maloy $e t a l$. (1980); malic enzyme, Cocaign-Bousquet et al. (1996). Acetaldehyde dehydrogenase was determined by measuring the rate of production of NADH as $A_{340}$ in $1 \mathrm{ml}$ cuvettes containing $70 \mu \mathrm{mol}$ phosphate buffer at $\mathrm{pH} 7 \cdot 5,20 \mu \mathrm{mol}$ acetaldehyde, $10 \mu \mathrm{mol} \beta$-mercaptoethanol and cell extract. Hydroxymuconate semialdehyde (2-hms) dehydrogenase was determined by measuring the rate of consumption of $2-\mathrm{hms}$ at $375 \mathrm{~nm}\left(\varepsilon_{375}=33000 \mathrm{M}^{-1} \mathrm{~cm}^{-1}\right.$ at $\left.\mathrm{pH} 7.5\right)$ in $1 \mathrm{ml}$ cuvettes containing $70 \mu \mathrm{mol}$ phosphate buffer at $\mathrm{pH} 7.5,0.1 \mu \mathrm{mol} 2-$ hms, $5 \mu \mathrm{mol} \mathrm{MgCl}_{2}, 10 \mu \mathrm{mol} \beta$-mercaptoethanol, $1 \mu \mathrm{mol}$ NAD, and cell extract.

Specific activities are expressed relative to the protein content of the cell-free extracts as measured by the Lowry method using bovine plasma albumin as standard.

Metabolic flux analysis. The conversion of enzyme specific activities to maximum flux capacities of whole cells was achieved by correcting the specific activity measurements to take into account the soluble protein content of the cells, thereby enabling direct comparison between enzyme activity measurements and in vivo flux through the catabolic pathways. These in vivo fluxes were calculated from specific rates of substrate consumption and growth and the stoichiometric matrix necessary to furnish catabolic intermediates and energy requirements for the anabolic pathways of macromolecule synthesis (Ingraham et al., 1983) using the approach described by Vallino \& Stephanopoulos (1993). The method was adapted to take into account the metabolic pathways of A. eutrophus (Schobert \& Bowien, 1984; Ampe \& Lindley, 1996), though in the present study we used the macromolecular composition specific for A. eutrophus (Ampe et al., 1997) rather than biomass composition data for E. coli.

Extraction and estimation of intracellular NAD/NADH concentration. The extraction procedure optimized by LeBloas $e t$ al. (1993) was used. Intracellular metabolites were assayed by measuring the increase (or decrease) of NADH fluorescence in the enzyme-coupled reactions described by LeBloas et al. (1993), using a spectrofluorometer. The excitation wavelength was $350 \mathrm{~nm}$ and the emission wavelength was $460 \mathrm{~nm}$. The intracellular metabolite concentrations were expressed as molar concentrations using the intracellular water content value of $1.9 \mu \mathrm{l}(\mathrm{mg} \text { dry cell } \mathrm{wt})^{-1}$ measured by thermogravimetry (Uribelarrea et al., 1985).

Determination of intracellular $\mathbf{p H}$. The cross-membrane $\mathrm{pH}$ gradient $(\Delta \mathrm{pH})$ was assayed by measuring the accumulation of ${ }^{14} \mathrm{C}$-labelled benzoate in cells centrifuged through silicone oil following a $3 \mathrm{~min}$ incubation period at $30^{\circ} \mathrm{C}$, as described by Loubiere et al. (1992). The intracellular volume of $1.9 \mu \mathrm{l}(\mathrm{mg} \text { dry cell wt })^{-1}$ measured for $\operatorname{NAD}(\mathrm{H})$ analysis was used to calculate the intracellular accumulation of benzoate. Benzoate was chosen since no expression of the benzoatedegrading pathway can be detected during growth on phenol.

Chemicals. All substrates, enzymes, coenzymes and radioisotopes were analytical grade and obtained from either Sigma or Boehringer Mannheim except for 2-hms, which is not available commercially and was therefore synthesized by the procedure described by Feist $e$ t al. (1969).

\section{RESULTS AND DISCUSSION}

With initial phenol concentrations lower than $2 \mathrm{mM}$, batch cultures showed a classical profile of exponential growth with a specific growth rate of $0.36 \mathrm{~h}^{-1}$, a specific

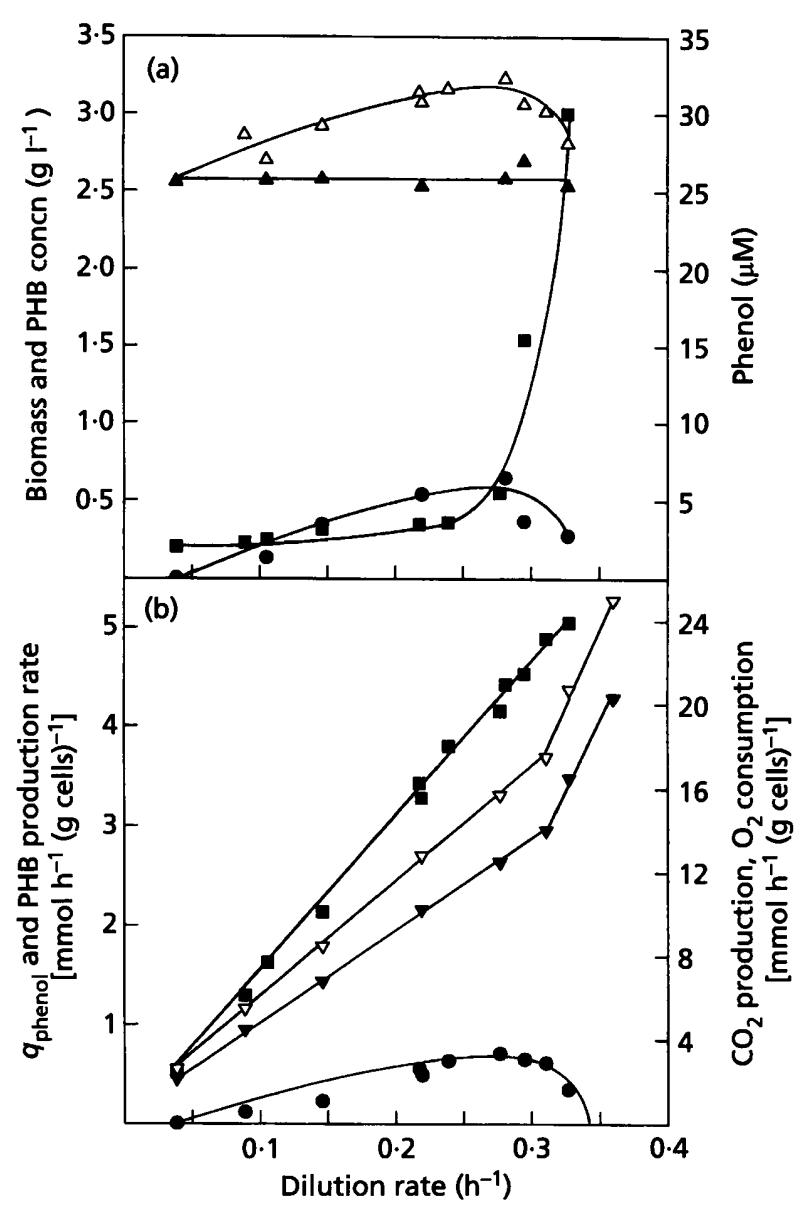

Fig. 1. Kinetics of growth and substrate consumption of $\boldsymbol{A}$. eutrophus in continuous culture on phenol. (a) Steady-state concentrations of total biomass including PHB $(\triangle)$, active biomass ( $\triangle$ ), PHB (O), and phenol $(\square)$; (b) specific rates of phenol consumption $(\square), \mathrm{O}_{2}$ consumption $(\nabla), \mathrm{CO}_{2}$ production $(\nabla)$, and PHB accumulation (O). 
Table 1. Energetic data deduced from stoichiometric and flux distribution analyses of steady-state chemostat cultures of $A$. eutrophus grown on phenol

\begin{tabular}{|c|c|c|c|c|c|c|c|}
\hline & \multicolumn{7}{|c|}{ Dilution rate $\left(h^{-1}\right)$ : } \\
\hline & 0.04 & 0.09 & $0 \cdot 15$ & 0.22 & $0 \cdot 28$ & 0.31 & $0 \cdot 33$ \\
\hline \multicolumn{8}{|c|}{ Catabolic coenzyme production } \\
\hline $\mathrm{NAD}(\mathrm{P}) \mathrm{H}$ & $2 \cdot 85$ & $5 \cdot 37$ & 8.56 & $12 \cdot 17$ & $14 \cdot 32$ & $17 \cdot 35$ & $20 \cdot 20$ \\
\hline FADH & 0.66 & $1 \cdot 20$ & 1.87 & $2 \cdot 62$ & 3.03 & 3.76 & 4.52 \\
\hline ATP & $-1 \cdot 12$ & $-3 \cdot 02$ & $-5 \cdot 15$ & $-8 \cdot 43$ & $-11 \cdot 14$ & -11.62 & $-10 \cdot 89$ \\
\hline \multicolumn{8}{|c|}{ Anabolic coenzyme demand } \\
\hline $\mathrm{NAD}(\mathrm{P}) \mathrm{H}$ & $0 \cdot 60$ & $1 \cdot 38$ & $2 \cdot 25$ & $3 \cdot 40$ & $4 \cdot 28$ & $4 \cdot 80$ & $5 \cdot 10$ \\
\hline ATP & 1.57 & 3.63 & 5.96 & $8 \cdot 97$ & $11 \cdot 30$ & $12 \cdot 69$ & $13 \cdot 46$ \\
\hline Apparent ATP excess & $2 \cdot 69$ & $2 \cdot 94$ & $2 \cdot 64$ & 3.63 & $1 \cdot 68$ & 5.79 & 11.89 \\
\hline Carbon recovery & 100 & 102 & 101 & 101 & 100 & 100 & 101 \\
\hline Redox recovery & 96 & 101 & 96 & 98 & 100 & 96 & 97 \\
\hline
\end{tabular}

rate of phenol consumption of $5.3 \mathrm{mmol}$ (g dry cell $\mathrm{wt})^{-1} \mathrm{~h}^{-1}$ and a biomass yield of $0.68 \mathrm{~g}$ cells $(\mathrm{g} \text { phenol })^{-1}$. At higher phenol concentrations, inhibition occurred, leading to an accelerating growth profile throughout the culture as the residual phenol concentration diminished. A similar phenomenon has been described for this organism during growth on benzoate (Ampe \& Lindley, 1996). This phenomenon, though interesting in its own right, makes characterization of phenol metabolism difficult due to the dynamic and rapid modifications throughout the fermentation. Because of this, continuous cultures were grown at different rates to establish kinetic parameters and identify bottlenecks which might explain why phenol metabolism is relatively slow compared to that of benzoate metabolized by the ortho pathway in A. eutrophus (Ampe \& Lindley, 1996).

\section{Biomass composition}

The cell density obtained for steady states increased as a function of the dilution rate until a dilution rate of $0 \cdot 28 \mathrm{~h}^{-1}$, while the residual phenol concentration was maintained at low values (Fig. 1). At higher rates of growth, some accumulation of phenol in the medium was observed and washout occurred at dilution rates close to $0.35 \mathrm{~h}^{-1}$, which is the maximum growth rate obtained in batch cultures. Microscopic observation of the cells taken from the chemostat showed the presence of dense inclusion bodies, similar to those seen in this bacterium during PHB accumulation. When checked by chemical analysis, it was confirmed that the variations in biomass concentration were due to a variable extent of PHB synthesis, with a constant biomass concentration being observed if PHB accumulation was allowed for. Thus, PHB content increased as a quasi-linear function of growth rate: a maximum value of $20 \%$ of biomass dry weight was observed at a dilution rate of $0.28 \mathrm{~h}^{-1}$ (Fig. 1). When the PHB content of cells was subtracted, a constant active biomass concentration was observed of $2.58 \mathrm{~g} \mathrm{l}^{-1}$. The production of PHB under carbon limitation is somewhat unusual since only negligible amounts of PHB are seen in carbon-limited chemostats of this bacterium grown on sugars (Mansfield et al., 1995). The maximum specific rate of PHB production observed in this study was $0.8 \mathrm{mmol}$ PHB $(\mathrm{g} \text { cells })^{-1} \mathrm{~h}^{-1}$, which was obtained for a phenol degradation rate of $4.5 \mathrm{mmol}$ phenol $(\mathrm{g} \text { cells })^{-1} \mathrm{~h}^{-1}$.

\section{Stoichiometry of phenol degradation}

The intracellular accumulation of PHB provoked an apparent variation in growth yield relative to phenol consumption. Active biomass concentration remained constant, however, leading to linear relationships between dilution rate and phenol degradation rate with a biomass yield of $0.68 \mathrm{~g}$ cells $\left(\mathrm{g}\right.$ phenol) ${ }^{-1}$. Similar linear relationships were seen for specific rates of $\mathrm{O}_{2}$ uptake and $\mathrm{CO}_{2}$ production, though both increased sharply at growth rates higher than $0.28 \mathrm{~h}^{-1}$ (Fig. 1). When extrapolated to zero growth rate, these linear relationships passed close to the origin, indicating that under such experimental conditions maintenance requirements were too low to be determined accurately by extrapolation (see below). For all steady states, full recovery of carbon was possible and redox balances based on the stoichiometry of each steady state were close to $100 \%$ (Table 1).

\section{Phenol degradation kinetics}

Maximal rates of phenol degradation were determined by pulse experiments and indicated a maximum phenol degradation capacity of $5.7 \pm 0.2 \mathrm{mmol}$ phenol (g cells $)^{-1} \mathrm{~h}^{-1}$, equivalent to $190 \mathrm{nmol}$ phenol (mg protein $)^{-1} \mathrm{~min}^{-1}$ when expressed as a function of soluble cell protein, irrespective of the dilution rate. The $\mathrm{O}_{2}$ uptake rate was high due to the dual role of oxygen, which is used directly in the oxidation of phenol at the levels of phenol hydroxylase and catechol-2,3dioxygenase but also for respiration, as seen from the respiratory coefficient of $0 \cdot 8$ seen at all dilution rates. 


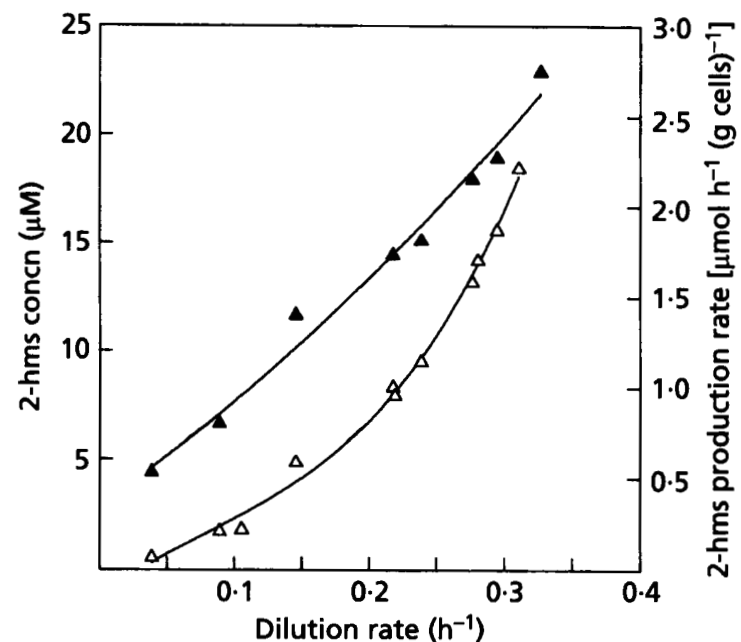

Fig. 2. Kinetics of 2-hms accumulation in continuous cultures of A. eutrophus on phenol. $\Delta, 2$-hms concentration; $\Delta, 2$-hms production rate.

\section{Accumulation of intermediary metabolite}

A yellow colour whose spectrum was consistent with the presence of 2-hms accumulated in the chemostat as a function of the dilution rate (Fig. 2), though no other intermediates of the meta pathway could be detected in culture filtrates when analysed by HPLC. At dilution rates higher than $0.28 \mathrm{~h}^{-1}$ trace amounts of acetate were seen in the medium. Since the rate of phenol consumption was a linear function of the growth rate, the rate of 2 -hms accumulation may equally well be expressed as a function of the phenol degradation rate. The rate of accumulation was low, $2.3 \mu \mathrm{mol}$ (g cells) $)^{-1} \mathrm{~h}^{-1}$, reaching a maximal steady state concentration of $22 \mu \mathrm{M}$. Similar accumulation of $2-\mathrm{hms}$ was also seen towards the end of batch cultures and seemed always to be directly related to the rate of phenol degradation. The $\mathrm{p} K_{\mathrm{a}}$ of $2-\mathrm{hms}$ was determined to be $2 \cdot 8$ by titration techniques. In view of the molecule's structure, it might be expected to diffuse passively across the cell membrane as the free acid, equilibrating as a function of the cross-membrane $\mathrm{pH}$ gradient $\langle\mathrm{pH}=$ $0.7 \pm 0.1$ as measured by accumuulation of ${ }^{14} \mathrm{C}$-labelled benzoate). As such, the intracellular concentration of 2-hms can be estimated to be in the order of $150 \mu \mathrm{M}$ when its concentration in the medium was maximal (i.e. $22 \mu \mathrm{M}$ ).

\section{Enzyme activity profiles}

The specific activity of various catabolic enzymes was assayed in cells from each steady state to determine whether the kinetic behaviour of the culture could be explained from potential limitations within the catabolic pathways. Three enzymes, representing the initial reactions of the meta cleavage pathway, were examined: phenol hydroxylase, catechol-2,3-dioxygenase and 2hms dehydrogenase. The activity of phenol hydroxylase,

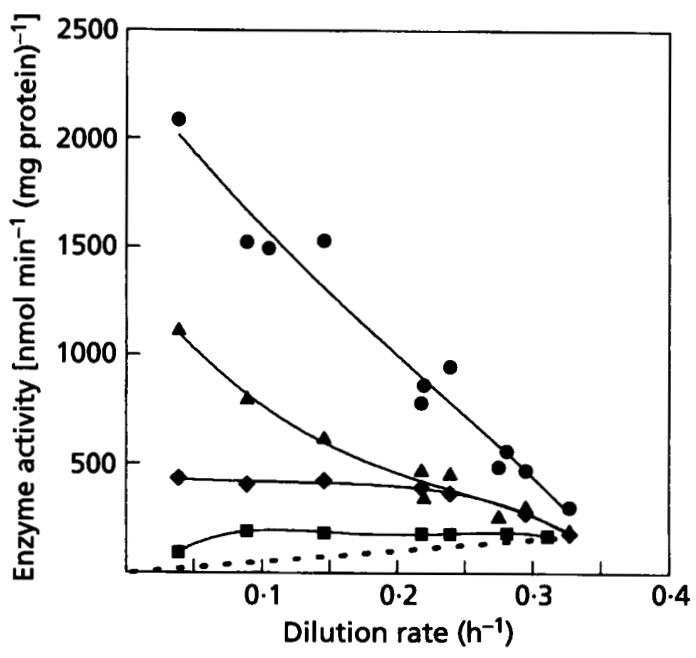

Fig. 3. Specific activities of enzymes associated with phenol degradation as a function of the dilution rate. $\square$, Phenol hydroxylase;, catechol-2,3-dioxygenase; $\boldsymbol{\Delta}$, 2-hms dehydrogenase; $\bullet$, acetyl-CoA synthetase. The theoretical flux which passes through the catabolic pathway (calculated from $q_{\text {phenol }}$ and a biomass composition of $50 \%$ soluble proteins) is shown by the dashed line.

leading to catechol, remained constant at all dilution rates, except for $0.04 \mathrm{~h}^{-1}$, when a lower specific activity was measured (Fig. 3). When extrapolated to whole-cell oxidation capacity the measured specific activity represented a value of $5 \cdot 50 \pm 0.25 \mathrm{mmol}$ phenol $(\mathrm{g} \text { cells })^{-1} \mathrm{~h}^{-1}$ (mean $\pm \mathrm{sE}, n=3$ ). This value was close to the maximum rate of phenol consumption obtained during exponential batch growth and, furthermore, corresponds to the maximal rate of phenol degradation observed when phenol was pulsed into phenol-limited chemostat cultures (see above).

Further oxidation of catechol involving the incorporation of molecular oxygen occurs via catechol-2,3dioxygenase to produce $2-\mathrm{hms}$, which is transformed via 2 -hms dehydrogenase activity to yield oxalocrotonate. The specific activity of both these enzymes was measured in cell extracts and shown to decrease as the growth rate increased (Fig. 3). Since the genes encoding the other enzymes of the meta pathway are believed to be contained in the same operon as the two enzymes examined here, it is probable that they show similar activity profiles with respect to growth rate.

The specific activity of 2-hms dehydrogenase was close to the measured rate of phenol consumption at the highest stable dilution rate established. An apparent affinity $\left(K_{\mathrm{m}}\right)$ of 2-hms dehydrogenase for 2-hms of $27 \mu \mathrm{M}$ was obtained together with a $K_{\mathrm{m}}$ of $30 \mu \mathrm{M}$ for NAD. Inoue et al. (1995) measured the same kinetic parameters in the case of $P$. putida and obtained a $K_{\mathrm{m}}$ value of $17 \mu \mathrm{M}$ for 2 -hms and $330 \mu \mathrm{M}$ for NAD. This enzyme was shown to be sensitive to the NADH:NAD ratio, with $50 \%$ inhibition at a ratio of 0.6 (results not shown) but such an in vivo modulation can be excluded 
since this ratio remained constant at 0.1 for all dilution rates. This value would not provoke significant inhibition. Since the intracellular concentration of 2-hms can be assumed to increase as a direct function of the observed extracellular accumulation and the $\Delta \mathrm{pH}$, it can be estimated that this enzyme was most probably substrate-saturated at the highest growth rates and therefore might be expected to have an important controlling influence on pathway flux.

The specific activity of catechol-2,3-dioxygenase, the enzyme postulated to be rate-limiting in P. putida $\mathrm{BH}$ (Fujita et al., 1993), was always higher than the pathway flux. Furthermore, no detectable accumulation of catechol was observed, in contrast to benzoate degradation by A. eutrophus (Ampe \& Lindley, 1996). However, the high affinity of this enzyme for catechol (apparent $K_{\mathrm{m}}$ $0.8 \mu \mathrm{M}$ ) would render detection of physiologically significant quantities of catechol difficult.

Since phenol degradation involves the production of molar quantities of acetaldehyde, which after oxidation to acetate is either catabolized by central metabolism or fed into PHB synthesis, the specific activities of various enzymes associated with acetate metabolism (acetylCoA synthetase, acetaldehyde dehydrogenase, isocitrate lyase, malate synthase and malic enzyme) were measured. The specific activities of all these enzymes remained constant at dilution rates lower than $0.28 \mathrm{~h}^{-1}$ but decreased thereafter, coincident with the appearance of trace amounts of acetate in the culture filtrates (see Fig. 3 for acetyl-CoA synthetase profile, which is typical of the other acetate associated enzymes). The exception was acetaldehyde dehydrogenase, whose specific activity remained constant at all dilution rates. This decrease in specific activity was not due to residual phenol accumulation since during washout in which phenol accumulated, provoking a diminishing growth rate, the specific activities increased once more (data not shown). A similar phenomenon was observed for catechol-2,3dioxygenase and 2-hms dehydrogenase. Thus, the specific activities of these enzymes seem to depend directly upon the growth rate. When rates of enzyme synthesis are calculated from specific activity measurements at steady state it can be seen that for the enzymes whose specific activities decrease at high dilution rates, a maximum rate of enzyme synthesis occurs at a dilution rate of $0.24 \mathrm{~h}^{-1}$, after which this rate diminishes. The physiological mechanism involved cannot be identified but it is interesting to note that this maximum of enzyme synthesis is coincident with a major change in behaviour leading to phenol accumulation and diminished levels of PHB accumulation.

During phenol metabolism, the activities of the glyoxylate shunt enzymes [isocitrate lyase specific activity $15 \pm 0.3 \mathrm{nmol}$ (mg protein) ${ }^{-1} \mathrm{~min}^{-1}$; malate synthase specific activity $55 \pm 3 \mathrm{nmol}(\mathrm{mg} \text { protein })^{-1} \mathrm{~min}^{-1}$ ] were fivefold lower than during growth on acetate. This pathway when operating provides the only manner in which acetyl-CoA can be fed into the gluconeogenic pathways and therefore the in vivo role of these enzymes during growth on phenol was examined by comparing

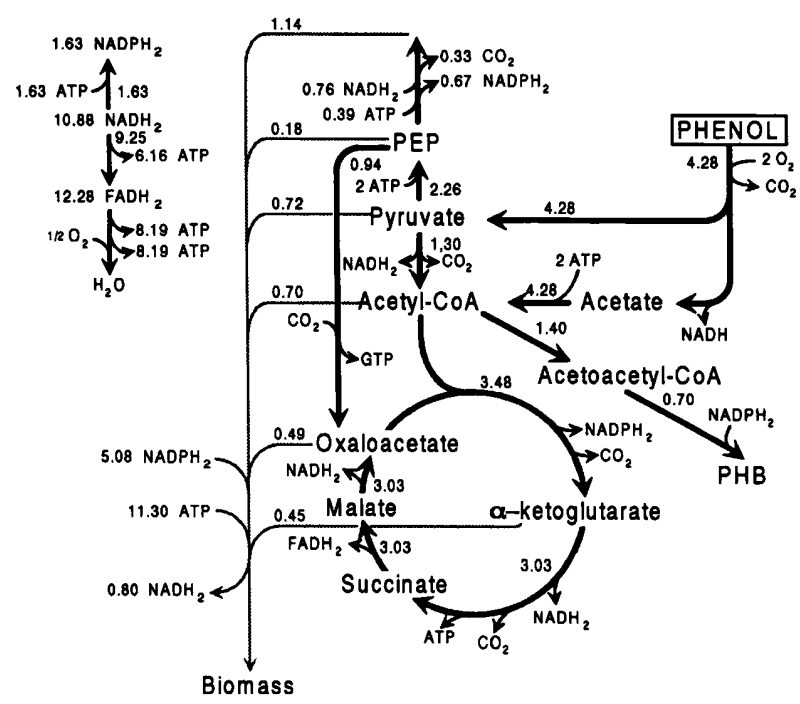

Fig. 4. Estimation of flux distribution within the central metabolic pathways based on the steady-state kinetic data from a continuous culture of $A$. eutrophus grown on phenol at a dilution rate of $0.28 \mathrm{~h}^{-1}$.

batch growth of transposon mutants lacking malate synthase activity. These mutants were unable to grow on acetate but were not affected in their growth on phenol (identical rates of growth and phenol consumption). It may therefore be concluded that the glyoxylate shunt is not necessary for growth on phenol and it is unlikely that any significant flux through this shunt occurs.

\section{Metabolic flux analysis and growth energetics}

The specific rates of substrate consumption, growth and product accumulation were used to estimate carbon flux distribution over the central metabolic network in light of the existing literature and the data provided by this study. Since phenol metabolism was unaffected in strains lacking malate synthase activity, the glyoxylate shunt has been removed from the network. As such, the acetate produced by the catabolic pathways of phenol degradation can either be oxidized by the tricarboxylic acid cycle with an important energy gain or converted to PHB. The absence of the shunt precludes the gluconeogenesis of acetate. The other metabolite resulting from phenol catabolism, pyruvate, can be directed either into gluconeogenesis or into the oxidative tricarboxylic acid cycle via pyruvate dehydrogenase. The carbon flux analysis (Fig. 4) shows that some pyruvate is oxidized via pyruvate dehydrogenase but that a majority of the pyruvate resulting from phenol degradation is used for gluconeogenesis and the production of the intermediary metabolites necessary for biomass synthesis. In view of the constant biomass yield obtained for the chemostat cultures, this distribution remained unchanged (though specific rates varied as a function of the growth rate) and the major variation in flux distribution concerned the fate of acetyl-CoA, which was metabolized via an oxidative tricarboxylic acid cycle or PHB synthesis in 


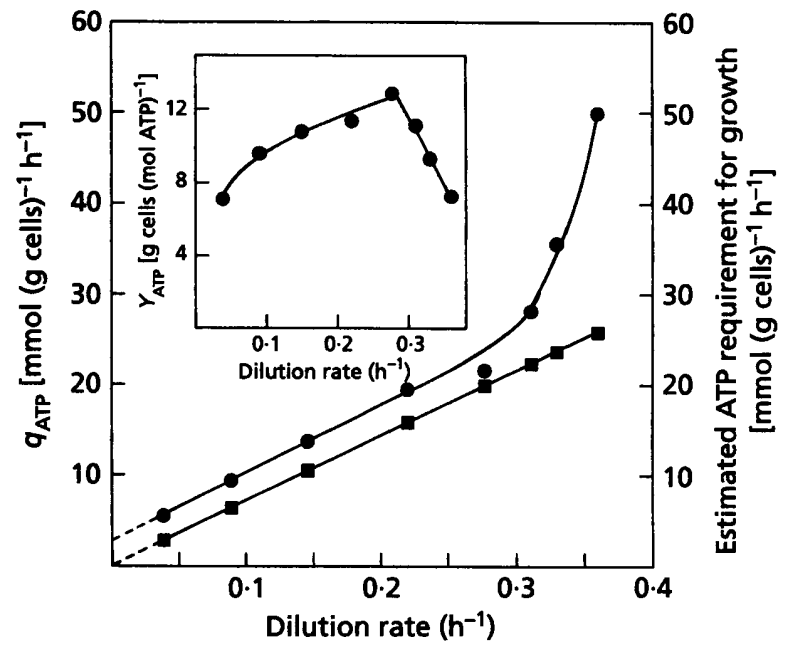

Fig. 5. Influence of the dilution rate on the energy metabolism of $A$. eutrophus. Main graph, specific rate of ATP production $(O)$ and theoretical ATP requirement for anabolism ( $\square$ ) during phenol catabolism determined from coenzyme flux estimations summarized in Table 1 . Inset, apparent $Y_{\text {ATP }}$-deduced rates of ATP synthesis and growth [theoretical $Y_{\text {ATP }}=13.95 \mathrm{~g}$ cells (mol ATP) $\left.{ }^{-1}\right]$.

proportions which varied with the dilution rate. Since $\mathrm{PHB}$ is produced at the expense of $\mathrm{CO}_{2}$ the possibility that PHB synthesis is acting as an energy sink to avoid excess production of biochemical energy was examined based upon the coenzyme yields associated with the carbon flux predictions.

After taking into account the reducing equivalents necessary for the anabolic pathways (Table 1), the remaining reduced coenzymes were converted to ATP via the respiratory chain. The respiration of $\mathrm{NAD}(\mathrm{P}) \mathrm{H}$ and FADH for ATP production was calculated using $\mathrm{P} / \mathrm{O}$ ratios of 2 for $\mathrm{NAD}(\mathrm{P}) \mathrm{H}$ and 1.33 for $\mathrm{FADH}$. The experimental $\mathrm{O}_{2}$ consumption rate agrees well with this estimated flux once additional $\mathrm{O}_{2}$ consumption directly linked to dioxygenase reactions is allowed for. The amount of ATP (or more precisely the rate of ATP synthesis) estimated to be available to the cells was compared to the amount theoretically necessary for anabolic purposes (Ingraham et al., 1983). A constant apparent overproduction was seen up to a dilution rate of $0.28 \mathrm{~h}^{-1}$, after which ATP availability appears to far exceed demand, probably due to energy-consuming inhibition phenomena linked to phenol accumulation. This overproduction $\left(2.5 \mathrm{mmol}\right.$ ATP $\left.\mathrm{g}^{-1} \mathrm{~h}^{-1}\right)$ agrees well with the value obtained by extrapolating the linear plot to zero growth rate and can be considered as a maintenance requirement. Indeed the value is remarkably close to that obtained during benzoate metabolism with this strain (Ampe \& Lindley, 1996). This activity can be assumed to remain constant and as such would explain the variable proportion of acetate channelled into PHB synthesis. Indeed in the absence of a functional glyoxylate shunt during phenol metabolism, acetate cannot contribute significantly to biomass synthesis and can therefore be considered predominantly as an energy source. The possibility to transform acetate to an easily mobilized intracellular carbon and energy reserve is clearly of selective advantage to the strain. The alternative would be overflow of acetate, which is known to repress phenol hydroxylase activity (Hughes \& Bayly, 1983) and hence diminish the growth capacity of the cell. Since some pyruvate is metabolized via pyruvate dehydrogenase, A. eutrophus could in theory further improve growth efficiency by controlling the flux through this enzyme but this would require a control structure responding to growth rate and would probably be of disadvantage to the strain during growth on other substrates. It is interesting to note that the flux through pyruvate dehydrogenase is approximately that necessary for anabolic requirements (acetyl-CoA and 2-oxoglutarate).

Since energy availability is apparently not a problem except at very low growth rates, the factors limiting maximum growth rates need to be examined. Since growth on benzoate, which is metabolized via the ortho pathway, is considerably more rapid (Ampe \& Lindley, 1996) than observed here for phenol, rate limitations are most probably localized within the specific pathway of phenol degradation. The relatively low growth rates are probably due to the poor level of catabolic enzyme expression. This is most obvious for 2-hms dehydrogenase and phenol hydroxylase, which are saturated at maximum growth rates. However, the profile of specific activity of other catabolic enzymes involved in phenol metabolism suggests that pathway flux control will be shared among several enzymes, including those metabolizing the acetaldehyde residue. Other micro-organisms are able to grow on phenol somewhat more rapidly than A. eutrophus and might therefore be expected to possess either more efficient pathways or higher levels of gene expression. In the case of $P$. putida $\mathrm{BH}$, the amplification of catechol-2,3-dioxygenase improved growth and enabled Fujita et al. (1993) to conclude that this enzyme was rate-limiting in the wild-type strain. It is interesting to note that although growth was improved, the higher rates of phenol degradation in the modified strain were accompanied by accumulation of $2-\mathrm{hms}$, indicating a shift in the control structure of the pathway. Unlike A. eutrophus, P. putida BH contains two enzymes able to degrade 2-hms, 2-hms dehydrogenase and a 2$\mathrm{hms}$ hydrolase. This additional mechanism of 2-hms degradation probably explains why the rate limitation was primarily located at the level of catechol-2,3dehydrogenase. In view of the probable control structure of the catabolic pathway of phenol degradation, which appears to have been optimized such that no individual enzyme plays a major bottleneck role, genetic improvement of phenol degradation will be difficult to achieve in A. eutrophus.

\section{REFERENCES}

Ampe, F. \& Lindley, N. D. (1995). Acetate utilisation is inhibited by benzoate in Alcaligenes eutrophus: evidence for transcriptional control of the expression of acoE coding for acetyl-CoA synthetase. J Bacteriol 177, 5826-5833. 
Ampe, F. \& Lindley, N. D. (1996). Flux limitations in the ortho pathway of benzoate degradation of Alcaligenes eutrophus: metabolite overflow and induction of the meta pathway at high substrate concentrations. Microbiology 142, 1807-1817.

Ampe, F., Aragao, G. M. F., Uribelarrea, J. L. \& Lindley, N. D. (1997). Benzoate degradation via the ortho pathway in Alcaligenes eutrophus is perturbed by succinate. Appl Environ Microbiol 63, 2765-2770.

Aragao, G. M. F., Lindley, N. D., Uribelarrea, J. L. \& Pareilleux, A. (1996). Maintaining a controlled residual growth capacity increases the production of polyhydroxyalkanoate copolymers by Alcaligenes eutrophus. Biotechnol Lett 18, 937-942.

Cocaign-Bousquet, M., Guyonvarch, A. \& Lindley, N. D. (1996). Growth rate-dependent modulation of carbon flux through central metabolism and the kinetic consequences for glucoselimited chemostat cultures of Corynebacterium glutamicum. Appl Environ Microbiol 62, 429-436.

Feist, C. F. \& Hegeman, G. D. (1969). Phenol and benzoate metabolism by Pseudomonas putida: regulation of tangential pathways. J Bacteriol 100, 869-877.

Folsom, B. R., Chapman, P. J. \& Pritchard, P. H. (1990). Phenol and trichloroethylene degradation by Pseudomonas cepacia G4: kinetics and interactions between substrates. Appl Environ Microbiol 56, 1279-1285.

Fujita, M., Ike, M. \& Kamiya. (1993). Accelerated phenol removal by amplifying the gene expression with a recombinant plasmid encoding catechol-2,3-oxygenase. Water Res 27, 11-17.

Ghisalba, O. (1983). Microbial degradation of chemical waste, an alternative to physical methods of waste disposal. Experientia 39, 1247-1257.

Herman, H. \& Muller, C. (1995). Localization and organization of phenol degradation genes of Pseudomonas putida strain $\mathrm{H}$. Mol Gen Genet 247, 240-246.

Hill, G. A. \& Robinson, C. R. (1975). Substrate inhibition kinetics: phenol degradation by Pseudomonas putida. Biotechnol Bioeng 121, 272-285.

Hughes, E. J. \& Bayly, R. C. (1983). Control of catechol metacleavage pathway in Alcaligenes eutrophus. J Bacteriol 154, 1363-1370.

Ingraham, J. L., Maaloe, O. \& Neidhart, F. C. (1983). Growth of the Bacterial Cell. Sunderland, MA: Sinauer Associates.

Inoue, J., Shaw, J. P., Rekik, M. \& Harayama, S. (1995). Overlapping substrate specificities of benzaldehyde dehydrogenase (the $x y l C$ gene product) and 2-hydroxymuconic semialdehyde dehydrogenase (the $x y l G$ gene product) encoded by TOL plasmid pWW0 of Pseudomonas putida. J Bacteriol 177, 1196-1201.

Johnson, B. F. \& Stanier, R. Y. (1971). Dissimilation of aromatic compounds by Alcaligenes eutrophus. J Bacteriol 107, 468-475.

Kristensen, C. S., Eberl, L., Sanchez-Romero, J. M., Givskov, M., Molin, S. \& de Lorenzo, V. (1995). Site-specific deletions of chromosomically located DNA segments with the multimer resolution system of broad-host-range plasmid RP4. J Bacteriol 177, 52-58.

Kukor, J. J. \& Olsen, R. H. (1991). Genetic organization and regulation of a meta cleavage pathway for catechols produced from catabolism of toluene, benzene, phenol, and cresols by Pseudomonas pickettii PKO1. J Bacteriol 173, 4587-4594.
LeBloas, P., Guibert, N., Loubière, P. \& Lindley, N. D. (1993). Growth inhibition and pyruvate overflow during glucose metabolism of Eubacterium limosum are related to a limited capacity to reassimilate $\mathrm{CO}_{2}$ by the acetyl-CoA pathway. J Gen Microbiol 139, 1861-1868.

Li, J. \& Humphrey, A. (1989). Kinetic and fluorometric behaviour of a phenol fermentation. In Bioprocess Engineering, pp. 190-206. Edited by T. K. Ghose. Chichester: Ellis Horwood.

Linko, S., Vaheri, H. \& Seppala, J. (1993). Production of poly- $\beta$ hydroxybutyrate by Alcaligenes eutrophus on different carbon sources. Appl Microbiol Biotechnol 39, 11-15.

Loubiere, P., Salou, P., Leroy, M.-J., Lindley, N. D. \& Pareilleux, A. (1992). Electrogenic malate uptake and improved growth energetics of the malolactic bacterium Leuconostoc oenos grown on glucose-malate mixtures. J Bacteriol 174, 5302-5308.

Maloy, S. R., Bohlander, M. \& Nunn, W. D. (1980). Elevated levels of glyoxylate shunt enzymes in Escherichia coli strains constitutive of fatty acid degradation. J Bacteriol 143, 720-725.

Mansfield, D. A., Anderson, A. J. \& Naylor, A. L. (1995). Regulation of PHB metabolism in Alcaligenes eutrophus. Can $J$ Microbiol 41, 44-49.

Mergeay, M., Nies, D., Schlegel, H. G., Gerits, J., Charles, P. \& van Cijsegem, F. (1985). Alcaligenes eutrophus $\mathrm{CH} 34$ is a facultative chemolithotroph with plasmid-bound resistance to heavy metals. $J$ Bacteriol 162, 328-334.

Nordlund, I., Powlowski, J. \& Shingler, V. (1990). Complete nucleotide sequence and polypeptide analysis of multicomponent phenol hydroxylase from Pseudomonas sp. Strain CF600. $J$ Bacteriol 172, 6826-6833.

Oberlies, G., Fuchs, G. \& Thauer, R. K. (1980). Acetate thiokinase and the assimilation of acetate in Methanobacterium thermoautotrophicum. Arch Microbiol 128, 248-252.

Paller, G., Hommel, R. K. \& Kleber, H.-P. (1995). Phenol degradation by Acinetobacter calcoaceticus NCIB 8250. J Basic Microbiol 35, 325-335.

Sala-Trepat, J. M. \& Evans, W. C. (1971). The meta cleavage of catechol by Azotobacter species. Eur J Biochem 20, 400-413.

Schobert, P. \& Bowien, B. (1984). Unusual C3 and C4 metabolism in the chemoautotroph Alcaligenes eutrophus. J Bacteriol 159, 167-172.

Schwien, U. \& Schmidt, E. (1982). Improved degradation of monochlorophenols by a constructed strain. Appl Environ Microbiol 44, 33-39.

Steinbuchel, A. \& Schlegel, H. G. (1991). Physiology and molecular genetics of poly ( $\beta$-hydroxyalkanoic acid) synthesis in Alcaligenes eutrophus. Mol Microbiol 5, 535-542.

Uribelarrea, J. L., Pacaud, S. \& Goma, G. (1985). New method for measuring the cell content by thermogravimetry. Biotechnol Lett 7, 175-180.

Vallino, J. J. \& Stephanopoulos, G. (1993). Metabolic flux distribution in Corynebacterium glutamicum during growth and lysine overproduction. Biotechnol Bioeng 41, 633-646.

Received 14 July 1997; accepted 22 September 1997. 